\title{
Atuação da Terapia Ocupacional no Consultório na Rua
}

\section{The Operation of Occupational Therapy in the "Street Clinic"}

\author{
Camila Prodocimo ${ }^{1}$, Glenda Milek $^{2}$, Sabrina Helena Ferigato ${ }^{3}$
}

http://dx.doi.org/10.11606/issn.2238-6149.v29i3p270-279

Prodócimo C, Milek G, Ferigato SH. Atuação da Terapia Ocupacional no Consultório na Rua. Rev Ter Ocup Univ Sao Paulo. 2018 set.-dez.;29(3):270-9.

RESUMO: Este artigo é resultado do trabalho de conclusão de curso intitulado "Corpos de criação: A atuação da Terapia Ocupacional no Consultório na Rua" e apresenta as contribuições da Terapia Ocupacional nas ações no Consultório na Rua. Objetivos: o estudo teve como objetivo geral conhecer e analisar a atuação da Terapia Ocupacional no Consultório na Rua junto às equipes e usuários deste dispositivo e como objetivos específicos buscou identificar, descrever e diferenciar as ações no campo da Atenção Primária em geral e no núcleo profissional junto à população atendida. Métodos: O estudo tem como enfoque uma pesquisa de abordagem qualitativa com caráter exploratório através da análise de cinco entrevistas semiestruturadas realizadas em 2017 com terapeutas ocupacionais em três municípios do estado de São Paulo. Resultados: As intervenções da Terapia Ocupacional no Consultório na Rua foram apresentadas em dois grupos I) ações do campo da Atenção básica e II) ações do núcleo da Terapia Ocupacional. Conclusão: A incorporação das terapeutas ocupacionais na equipe e no trabalho in loco, permitiu a ampliação de estratégias de cuidado, para além das ações curativas ou preventivas. Às ações de núcleo se apresentaram como uma das potências do serviço, ampliando a apropriação do usuário em relação à seu cuidado. Os terapeutas ocupacionais atuam principalmente proporcionando encontros, experimentações de si e do mundo por meio de atividades, frente as inúmeras possibilidades que a vida cotidiana na rua oferece.

Descritores: Terapia ocupacional; Atenção primária à saúde; Pessoas em situação de rua.
Prodócimo C, Milek G, Ferigato SH. The Operation of Occupational Therapy in the "street clinic". Rev Ter Ocup Univ Sao Paulo. 2018 Sept-Dec;29(3):270-9.

ABSTRACT: This article is the result of the course conclusion work titled "Bodies of creation: The performance of Occupational Therapy in the street clinic" and presents the contributions of Occupational Therapy in actions in the street clinic. Objectives: The objective of the study was to know and analyze the performance of Occupational Therapy in the street clinic with the professionals and users of this device and as specific objectives sought to identify, describe and differentiate actions in the field of Primary Care in general and in the professional nucleus with the population served. Methods: The study focuses on a qualitative research with an exploratory character through the analysis of five semi - structured interviews conducted in 2017 with occupational therapists in three municipalities in São Paulo state. Results: The interventions of Occupational Therapy in the Street clinics were presented in two groups: I) actions in the field of Basic Attention and II) occupational therapy specific actions. Conclusion: The incorporation of the occupational therapists in the team and the work in loco, allowed the expansion of strategies of care, in addition to curative or preventive actions. The core actions presented themselves as one of the powers of the service, increasing the appropriation of the user in relation to their care. Occupational therapists act mainly by providing encounters, experiencing themselves and the world through activities, in front of the innumerable possibilities that everyday life on the street offers.

Keywords: Occupational Therapy; Primary health care; Homeless persons.

1. Terapeuta ocupacional, Universidade Federal de São Carlos - UFSCar. E-mail: camilaprodocimo@gmail.com.

2. Terapeuta ocupacional do Consultório na Rua do Município de Santos. E-mail: glendamilek@hotmail.com.

3. Terapeuta Ocupacional, Docente adjunta do Departamento de Terapia Ocupacional da Universidade Federal de São Carlos

- UFSCar. E-mail: sabrinaferigato@gmail.com. 


\section{INTRODUÇÃO}

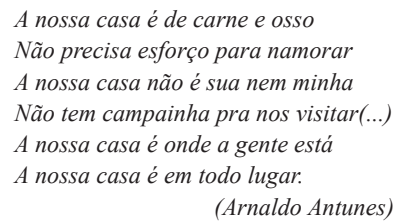

$\mathrm{O}^{\mathrm{a}}$ avanço do projeto neoliberal e a aceleração do processo de globalização produziu nas últimas décadas um aumento na geração de desigualdade social, bem como a ausência de garantias sociais para grande parte das populações ${ }^{1}$. Um contexto como esse é especialmente violento para àqueles denominados por Castel $^{2}$ como "sobrantes", pessoas normais, mas invalidadas pela conjuntura, como decorrência das novas exigências da competitividade, da concorrência e da redução de oportunidades e de emprego. Nesse contexto, é que se insere a população em situação de rua (PSR).

Considera-se a população em situação de rua o grupo populacional heterogêneo que possui em comum a pobreza extrema, os vínculos familiares interrompidos ou fragilizados e a inexistência de moradia convencional regular, e que utiliza os logradouros públicos e as áreas degradadas como espaço de moradia e de sustento, de forma temporária ou permanente, bem como as unidades de acolhimento para pernoite temporário ou como moradia $\operatorname{provisória}^{3}$ (p.16).

Por maior que seja a heterogeneidade dessa população, podemos dizer que um traço comum a maioria dessas pessoas, é a singular vivência de processos de exclusão.

Muitas são as estratégias que as políticas públicas, em diferentes setores, vêm construindo para o enfrentamento dessa problemática, reforçando a noção cidadã da PSR e sua condição como sujeitos de direitos. Dentre todas essas Políticas, focaremos especialmente nas políticas de saúde voltadas para essa população, com o recorte das ações da Atenção Primária em Saúde (APS), a partir da análise das ações do dispositivo de saúde voltado para as necessidades específicas de saúde das PSR: O Consultório na Rua (CnR).

A proposição da atuação profissional neste dispositivo parte das noções de autonomia, cidadania e de produção de singularidades como guias da interpretação da demanda e da formulação de projetos de intervenção ${ }^{4,5}$. Nessa direção, esse artigo tem como objeto a ação dos terapeutas ocupacionais, vinculados ao $\mathrm{CnR}$, junto à PSR, com o objetivo geral de conhecer e analisar as ações desenvolvidas por esses profissionais e como objetivos específicos identificar, descrever e diferenciar as ações nucleares dos terapeutas ocupacionais e as ações gerais realizadas no campo da APS.

\section{O SUS e a Atenção Básica em saúde no cuidado à PSR}

De acordo com o Plano Operativo para Implementação em Saúde da População em Situação de Rua (2013), os objetivos gerais das Políticas de Saúde em relação a essa população são: Garantir o acesso da PSR às ações e aos serviços de saúde, fomentar a implementação das equipes do CnR; reduzir os riscos à saúde decorrentes dos processos de trabalho na rua e das condições de vida; melhorar os indicadores de saúde e da qualidade de vida da PSR e desenvolver estratégias para promoção da saúde da PSR. Além disso, são destacadas como metas um conjunto de medidas que visam assegurar o acesso amplo, simplificado e seguro aos serviços e programas que integram as políticas públicas de saúde, educação, previdência, assistência social, moradia, segurança, cultura, esporte, lazer, trabalho e renda ${ }^{6}$.

Esses direcionamentos tecno-políticos são relevantes, no entanto, do ponto de vista operacional, esse ainda é um movimento contra-hegemônico. Na maior parte das vezes, em detrimento dos sujeitos assistidos, são priorizadas as práticas da clínica centrada na doença/problema. No caso específico das PSR, essas práticas em geral, vêm acompanhadas de processos de estigmatização e moralização dos usuários ou de processos assistencialistas/caritativos, o que dificulta um acesso com eficácia ao sistema.

Em 2009 o Ministério da Saúde propôs formalmente a implementação do serviço de Consultório de Rua como uma das estratégias do Plano Emergencial de Ampliação de Acesso ao Tratamento e Prevenção em Álcool e outras Drogas, ampliando o acesso aos serviços assistenciais por intermédio de ações de saúde na rua. Essa proposta foi incluída em 2010 no Plano Integrado Nacional de Enfrentamento ao Crack e outras Drogas, vinculado à coordenação nacional de saúde mental ${ }^{7}$.

Em 2011, através do Decreto Presidencial $n^{\circ}$ $7.053 / 2009^{3}$, o programa foi admitido como um dispositivo da ABS, com a mudança na nomenclatura 'de rua' para 'na rua'.

A Política Nacional de Atenção Básica (PNAB), caracteriza a Atenção Básica em Saúde (ABS) como "um conjunto de ações de saúde, no âmbito individual e coletivo, que abrange a promoção e a proteção da saúde, a prevenção de agravos, o diagnóstico, o tratamento, a reabilitação, a redução de danos e a manutenção da saúde, com o objetivo de desenvolver uma atenção integral que impacte na situação de saúde e autonomia das pessoas e nos determinantes e condicionantes de saúde das coletividades." 
A PNAB em suas diretrizes atualizou e avançou no reconhecimento do atendimento direcionado a PSR, facilitando as condições de acesso aos serviços. Municípios e áreas que não são cobertas pelo serviço do $\mathrm{CnR}$, tem “a responsabilidade pela atenção à saúde da PSR, como de qualquer outro cidadão, é de todo e qualquer profissional do SUS" $"$.

Esses aspectos introdutórios permitem compreender os motores que impulsionaram o desenvolvimento da proposta do Consultória na Rua, que por meio de recursos da ABS, promove uma porta de entrada nos serviços de atenção à saúde e às redes intersetoriais. Com esse dispositivo, propõe-se ampliar o cuidado à essa população in loco, buscando prestar atenção integral à saúde de pessoas que se encontram em condições de vulnerabilidade.

$\mathrm{O}$ atendimento in loco acontece de modo que o contexto da PSR seja respeitado, sendo repudiado qualquer forma de julgamento ou censura, já que os estigmas e discriminações que acompanham esta população em específico, são uma das principais causas da inacessibilidade aos serviços de saúde ${ }^{7}$.

\section{Consultório na Rua e a terapia ocupacional}

Compondo dispositivos da Saúde Mental e da Estratégia de Saúde da Família, o CnR foi implementado como serviço estratégico das redes de atenção em saúde (RAS) ${ }^{10}$ constituído por equipes de saúde móveis, desenvolvendo ações compartilhadas e integradas às UBS, CAPS, Serviços de Urgência e Emergência e outros pontos de atenção da rede setorial e intersetorial. Atualmente no Brasil existem 129 unidades móveis do $\mathrm{CnR}^{11}$.

Sua estrutura de funcionamento com uma equipe volante mínima com formação multidisciplinar, entre os quais, o terapeuta ocupacional. Atualmente existem 3 modalidades de constituição de equipes ${ }^{11}$ :

Modalidade I: quatro profissionais, entre os quais dois destes obrigatoriamente enfermeiros, psicólogos, assistentes sociais ou terapeutas ocupacionais e os demais entre as seguintes categorias: agente social, técnico ou auxiliar de enfermagem, técnico em saúde bucal, cirurgiãodentista, profissional/professor de educação física ou profissional com formação em arte e educação;

Modalidade II - Idem a modalidade I, acrescidos de mais 2 profissionais de nível superior, totalizando 6 profissionais, dos quais 3 obrigatoriamente deverão ser enfermeiros, psicólogos, assistentes sociais ou terapeutas ocupacionais;

Modalidade III - equipe da Modalidade II acrescida de um profissional médico.
O serviço é estruturado dentro de uma van/kombi/ ônibus, veículo possível de transitar entre os espaços da cidade. Contam com materiais médico-medicamentosos, de enfermagem, além de recursos para atividades plásticas/ artesanais.

O primeiro Consultório de Rua foi desenvolvido em 1999 na cidade de Salvador, BA, inserido em um CAPS $\mathrm{AD}$, como um projeto-piloto, no qual focava o acesso a adolescentes e crianças que faziam uso de substâncias psicoativas, oferecendo assistência através de intervenções com a PSR ${ }^{12}$.

Neste contexto, o estado de São Paulo, destaca-se por seu protagonismo em relação ao movimento da Redução de Danos, que se inicia em Santos na década de 80, no entanto, não foram localizados dados específicos em relação ao Consultório na Rua no Estado, mesmo em fontes formais do Ministério da Saúde e Secretaria Estadual.

Como referência teórica os $\mathrm{CnR}$ adotam a abordagem da Redução de Danos (RD) como uma das estratégias norteadoras das ações das equipes. Caracterizada inicialmente como estratégia de abordagem em relação à prevenção/ tratamento das doenças sexualmente transmissíveis (DSTs) e consumo substâncias psicoativas, a RD se apresenta como uma direção de cuidado, ressignificando o tratamento como busca pela ampliação dos graus de liberdade e de coresponsabilização do usuário. A RD considera as tramas e redes que fazem parte da vida dos sujeitos, desfocando o olhar centrado nas drogas ou da doença, trazendo à cena o território existencial dos usuários ${ }^{13}$.

\section{A terapia ocupacional junto ao cuidado com a PSR}

Terapeutas ocupacionais deparam-se com o atendimento de PSR, em diferentes campos de atuação, entre os quais, podemos citar, a APS, a saúde mental, a assistência social, a atenção hospitalar, instituições de longa permanência, entre outros. No entanto, muitas vezes, a situação na rua não é diretamente o aspecto que promoveu o encontro entre terapeuta ocupacional e a PSR, sendo esse encontro mediado, por exemplo, pela inserção em uma rede de serviços socioassistencial, no acometimento de algum transtorno mental ou outros tipos de sofrimento em saúde. Já na experiência vivenciada por profissionais que atuam no $\mathrm{CnR}$, estar nesta condição existencial de utilizar a rua como moradia, é justamente o que proporcionou ao usuário a possibilidade de encontro com um terapeuta ocupacional.

A ação deste profissional se dá no campo de uma proximidade expressiva, em compromisso com o público assistido em reconhecer suas demandas, compreender suas necessidades e buscar as mudanças que se fizerem 
necessárias por meio de interferências em seu cotidiano e em suas atividades ${ }^{5}$.

A ruptura de vínculos, a exclusão do mercado de trabalho e da família, são muitas vezes instabilidades que alimentam as extensões que estas fragilidades causam no cotidiano do sujeito em situação de rua, que passa a ser a vivenciar a condição de vulnerabilidade e/ou rompimento com suas redes de suporte ${ }^{4,5}$.

A terapia ocupacional, tem como uma de suas potencialidades, o trabalho extra muros, em diferentes âmbitos territoriais, em cenários concretos de vida. Nesses espaços, a relação com a realidade do sujeito em ação se apresenta como um dispositivo para o enfrentamento de estigmas, de problemáticas cotidianas, onde o sujeito produz as potências de sua própria vida ${ }^{14}$.

O trabalho do terapeuta ocupacional no $\mathrm{CnR}$ fortalece seu espaço na $\mathrm{ABS}$, antes restrito às Unidades Básicas de Saúde (UBS), Unidades de Saúde da Família (USF) e Núcleo de Apoio à Saúde da Família (NASF).

A Terapia Ocupacional na ABS visa atender diferentes necessidades em saúde, construindo junto aos sujeitos individuais e coletivos a possibilidade de serem protagonistas de seu processo de vida. Neste espaço, "evidenciam-se conflitos para os quais é preciso buscar equacionamentos singulares. Trata-se de buscar os sentidos que são constantemente atribuídos à ação individual e à ação coletiva, ambas inseridas em processos históricos de negociação cultural" (p.94) ${ }^{15}$.

Para esse equacionamento, os amplos direitos relacionados à cidadania servem como um dos guias da identificação das reais demandas dos sujeitos e para construção de projetos de intervenção para grupos populacionais como as PSR, para que o terapeuta ocupacional possa atender singularmente as necessidades desses sujeitos singulares ${ }^{15}$.

Por compreendermos que as contribuições desse núcleo profissional são significativas para a construção da proposta do $\mathrm{CnR}$, temos como objetivo nos aprofundar em relação a essas contribuições, sistematizando-as, a partir da narrativa e experiência de terapeutas ocupacionais atuantes nesse campo.

\section{ASPECTOS METODOLÓGICOS}

O presente estudo tem como enfoque uma pesquisa de abordagem qualitativa com caráter exploratório. A produção de dados se baseou no procedimento de entrevistas individuais semiestruturadas com Terapeutas Ocupacionais que compõem as equipes de trabalho no $\mathrm{CnR}$ e/ou que atuem diretamente em interface com as equipes do $\mathrm{CnR}$. A informante inicial foi escolhida por critério de conveniência e por se tratar de terapeuta ocupacional com experiência clínica no Consultório na Rua e junto à população de rua. O critério de indicação das entrevistadas se deu pela amostragem da bola de neve que parte do contato com um informante-chave e através dele, se localiza através de indicações, pessoas que possuem o perfil necessário para a construção da pesquisa. $\mathrm{O}$ processo se encerra através da saturação de nomes oferecidos por cada informante ${ }^{16}$. Entre as indicadas tivemos duas perdas: uma por situação de falecimento e uma por recusa em participar.

Entre os critérios de inclusão foi previsto que os participantes deveriam ser graduados(as) em terapia ocupacional, estar vinculado à um Consultório na Rua do estado de São Paulo ou à algum serviço de saúde que realize ações de apoio matricial às equipes do $\mathrm{CnR}$; estar atuando na rede pública há pelo menos seis meses e aceitar participar voluntariamente da pesquisa ao assinar o TCLE.

As entrevistas com os terapeutas ocupacionais foram realizadas de forma presencial (nos locais de trabalho indicados das entrevistadas), áudio-gravadas, sendo apenas uma, realizada virtualmente por solicitação da entrevistada. Todas as entrevistas foram posteriormente transcritas para análise.

Para a produção de dados foi utilizado como instrumento um roteiro de entrevista previamente construído pelos pesquisadores que incluíam dados gerais das participantes, questões semiestruturadas sobre o trabalho de campo da atenção básica junto à população de rua e por fim, dados sobre o núcleo da terapia ocupacional.

O período para a realização da pesquisa de campo foi de 6 meses (maio a outubro de 2017), e para que não houvesse qualquer tipo de constrangimento, a confidencialidade das entrevistadas foi estruturada por numerações, conforme as ordens de realização das entrevistas.

A análise dos dados se constituiu a partir do referencial metodológico da análise temática proposta por Minayo $^{17}$. Segundo essa abordagem, o procedimento de análise é desenvolvido primeiramente através do material coletado/produzido por meio da leitura, para que se busque a orientação para análise dos dados, definindo e registrando as primeiras impressões que se desdobra nas etapas de pré-análise, exploração do material e na elaboração de uma síntese dos dados. Posteriormente a esse processo, os resultados foram sistematizados em eixos temáticos.

Essa pesquisa foi aprovada em 2017 pelo Comitê de Ética em Pesquisa, com o código 68141317.2.0000.5504 


\section{RESULTADOS E DISCUSSÃO}

\section{Caracterização das Participantes}

As entrevistas foram realizadas com 5 terapeutas ocupacionais em três municípios, todas do gênero feminino, com idade média de 30 anos, com tempo de formação que variou de 1 ano até 18 anos desde a conclusão do curso, todas no estado de São Paulo.

Das 5 entrevistadas, 2 trabalhavam como terapeuta ocupacional dentro do serviço do $\mathrm{CnR} ; 2$ trabalhavam no CAPS AD em articulação direta com a PSR e equipe do $\mathrm{CnR}$ via apoio matricial e 1 é residente do programa de saúde mental e saúde coletiva da UNICAMP inserida integralmente no $\mathrm{CnR}$ por contrato formal entre Instituição de ensino e serviço. Todas atendiam aos critérios de inclusão na pesquisa.

\section{Ações do campo da ABS no CnR}

O conceito de campo e núcleo proposto por Campos $^{18}$, revela que no cotidiano do trabalho da equipe, há o processo de conhecimento do núcleo de cada área profissional e do campo onde se inserem. O núcleo é caracterizado como a identidade de uma área de saber, da prática profissional de uma categoria em específico; já as ações compartilhadas entre os diferentes núcleos se definem como ações do campo.

A linha tênue entre o trabalho de núcleo e o trabalho de campo são confrontadas dia após dia pelos profissionais que buscam apoio e compartilhamento entre si, sem perderem a especificidade de seu saber disciplinar.

A Terapia Ocupacional, assim como os outros profissionais da equipe, possuem suas especificidades, baseando seu trabalho em recursos materiais e imateriais, com ênfase na atividade humana e no cotidiano de sujeitos individuais e coletivos, no entanto, o trabalho em equipe se constrói em um borramento de fronteiras disciplinares em relação às ações do campo da $\mathrm{ABS}$ e as demandas intensivas que emergem das ruas.

As ações em campo enunciadas pelas entrevistadas se apresentaram abordando especialmente duas categorias de análise (1) a dinâmica de trabalho do serviço e (2) às ações de cuidado em rede.

(1) A dinâmica do trabalho da equipe do $\mathrm{CnR}$ inclui ações de promoção, prevenção, tratamento e reabilitação realizadas pelos profissionais do $\mathrm{CnR}$ em articulação com as UBS, USF, CAPS e demais equipamentos da rede de atenção setorial e intersetorial.

Para a eficácia dessa dinâmica, a função da gestão é destacada como importante para garantir a efetividade da equipe volante bem como sua articulação com os demais serviços "estáticos".

Do ponto de vista dos princípios que norteiam as práticas da equipe, é citada a perspectiva da $\mathrm{RD}$, por todas as entrevistadas.

A partir dessa perspectiva o CnR propõe a garantia e a construção de acesso aos direitos dos usuários, abrindo o caminho para que consigam acessar os serviços da rede de saúde e de suporte.

\footnotetext{
"Apesar dessa população, muitas vezes, pertencer a determinados territórios, ainda tem muitas dificuldades de acessar cuidados básicos em saúde. (...). Vamos até o local, abordamos/atendemos a pessoa que está em situação de rua e vemos quais são as necessidades dela naquele momento" (Terapeuta 5).

"Geralmente, acompanhamos a pessoa até as unidades de saúde, garantindo que os atendimentos aconteçam, que esse acesso ocorra" (Terapeuta 5).
}

Os atendimentos são realizados nos espaços da cidade onde se concentram a maior parte da PSR. Alguns pontos são considerados fixos pelo serviço, para fácil acesso aos usuários, que costumam permanecer mais tempo em locais específicos nos centros urbanos.

Regularmente realiza-se a busca ativa no território, de modo que outros usuários também possam receber o cuidado. Outros dispositivos também acionam o CnR para a busca ativa de usuários ou em situações em que precisam de informações sobre um usuário em atendimento.

\footnotetext{
"Acabamos por ficar nos territórios de atendimento para produzir vínculos com as pessoas. Se ficarmos muito "volantes", não conseguimos acompanhar os processos de cuidado da população, vínculo se produz também com presença... Nos flexibilizamos também nesses territórios, atendendo seus arredores, acabamos por nos estender" (Terapeuta 5).
}

Por conta desta mobilidade, os atendimentos podem ser realizados em apenas um acolhimento, até um acompanhamento mais longitudinal, estabelecendo um vínculo no cuidado do processo de saúde, acompanhando de perto os tratamentos, a medicação assistida, o resgate de direitos, a RD, o autocuidado, etc.

"Depende de quanto tempo ele vai ficar na cidade, se a gente observa que precisa de um cuidado mais intensivo a gente acaba encaminhando, senão a gente dá conta na rua" (Terapeuta 3).

Pelo fato do trabalho ser realizado por uma equipe interprofissional, o cuidado integral a saúde disponibiliza 
diversas práticas para proporcionar melhores condições de vida aos usuários em processos de cuidado compartilhados em ato.

\begin{abstract}
"É uma equipe muito impar, desde a técnica de enfermagem, a enfermeira, o psicólogo, a psicóloga, a TO, os médicos... geralmente estão a par de todos os casos, até porque os usuários circulam muito e como não existem salas, está todo mundo mais ou menos vendo o que está acontecendo, então acho que isso favorecia para a equipe estar bem apropriada mesmo, das questões de cada um" (Terapeuta 4).
\end{abstract}

A abordagem aos usuários, geralmente se dá de maneira espontânea, ou através da busca ativa. Em pontos fixos de atenção (que são aqueles locais em que o veículo comparece em datas e horários regulares) a população costuma ir até o serviço, por já conhecerem a oferta.

\begin{abstract}
"Vamos até estes territórios a cada dia da semana, fazemos as abordagens com as pessoas no local (avaliamos bem quais são os contextos e como devem ser essas abordagens) e outras vezes esperamos no nosso carro (uma van com identificação do CnR) e atendemos, conversamos com as pessoas que desejem um cuidado, uma atenção, uma escuta. Por acompanhar mais longitudinalmente alguns casos, muitas vezes temos que ir em busca dos usuários para acompanhamento, para saber como está, para entregar algum resultado de exame" (Terapeuta 5).
\end{abstract}

(2) Ações integrais de cuidado e ações em rede.

A articulação do $\mathrm{CnR}$ com a rede de serviços da saúde e de diferentes setores, é essencial no cuidado e corresponsabilização pelo usuário. Como a PSR possuem contextos de vida de vulnerabilidade extrema, outros atores devem estar envolvidos na atenção integral ao sujeito ${ }^{19}$.

De acordo com as entrevistadas, visando o cuidado integral, o CnR trabalha fazendo rede o dia todo sem descuidar do cuidado in loco, principal ação do CnR. O serviço consegue "dar conta" de uma série de demandas, porém não funciona efetivamente sem os outros equipamentos. Quando essa rede é falha, o CnR por um lado, "tapa alguns buracos na rede", e por outro acaba explicitando outras lacunas que ainda precisam ser preenchidas.

"Um trabalho que o tempo todo está esbarrando nas falhas tanto da rede de saúde quanto da assistência social e acho que isso é uma grande dificuldade" (Terapeuta 4)

"Em tudo que a gente percebe que existe a necessidade de fazer rede, o consultório faz" (Terapeuta 3)
Entre os limites apresentados pelas entrevistadas para a efetivação do cuidado em rede, destaca-se a dificuldade de acesso, inserção e permanência dos usuários do CnR em outros serviços da rede de saúde e intersetorial, não apenas pela mobilidade dos usuários, mas especialmente pela baixa co-responsabilização pelo cuidado de profissionais de outros serviços, sendo que parte importante do tempo da equipe é investido nisso.

\begin{abstract}
"Normalmente o caso que a gente consegue construir uma rede mais completa é aquele caso que dá mais um pouquinho de conta de estar transitando pelos serviços" (Terapeuta 1).

"Aqui é uma dificuldade para decidir uma demanda, o usuário tá em uma crise que advém de um transtorno mental grave + o uso de substância, e aífica na discussão se é um caso pra UBS, pro CAPS III, se é pro CAPS AD, é muito difícil partilhar esse cuidado, mais dificil ainda quando é alguém que está na rua” (Terapeuta 4).
\end{abstract}

Duas terapeutas mencionaram o potencial das parcerias com serviços da rede básica e especializada, além da rede de urgência e intersetorial (assistência social e com a defensoria pública).

Com essa rede, de acordo com as entrevistadas, o trabalho inclui ações de "desconstruir preconceitos", "acessar direitos" e "capacitar outros profissionais para o auxílio do cuidado em saúde da PSR, buscando articulações de equipamento para equipamento".

\footnotetext{
"Vejo que a rede é produzida em um trabalho artesanal mesmo, às vezes um contato em um serviço com algum trabalhador que esteja mais sensivel às necessidades dessa população, acaba "nos" acolhendo e assim, vamos fortalecendo os vínculos com os serviços. (...). Os desafios são grandes, mas nos apoiamos nos encontros potentes que temos com alguns dos trabalhadores e assim apostamos nessa atualização sobre o cuidado dos nossos usuários. Precisamos poder dizer que os usuários são "nossos" mesmo, da rede, da cidade e não apenas do CnR.” (Terapeuta 5).
}

\section{Ações do núcleo da Terapia Ocupacional}

No CnR foram identificadas especificidades da atuação deste profissional, que procuramos sistematizar nos eixos I) Aporte dos referenciais teóricos da Terapia Ocupacional, II) Relação com a equipe, III) Relação com a PSR e a rua como campo de trabalho, IV) $\mathrm{O}$ uso de atividades e o processo terapêutico ocupacional.

(I) Aporte dos referenciais teóricos da terapia ocupacional 
Três das entrevistadas exploram a questão da escolha pela abordagem prática sem citar um referencial específico da profissão. Referem que partem das necessidades do usuário ou referenciais interdisciplinares, antes de oferecer uma linha específica de cuidado a ele. Existe um cuidado em reavaliar as necessidades do usuário que

"por conta da dinamicidade do cotidiano na rua, sofre alterações constantes" (Terapeuta 1).

A Terapeuta 4 menciona que veio de uma formação voltada para a Terapia Ocupacional Dinâmica, mas que seus referenciais prévios não são utilizados com a população por conta da dinâmica de ações multiprofissionais que sê impõe no processo de trabalho.

"Eu sigo a linha da prática, que eu acho bem interessante assim, ir sempre avaliando o usuário” (Terapeuta 3)

"Eu acho que a Terapia Ocupacional na rua, exige uma flexibilidade de ações e de referenciais" (Terapeuta 4).

A Terapeuta 5 relata que sua prática está embasada nos preceitos da Terapia ocupacional como produção de vida, da Esquizoanálise e na Cartografia. Em sua fala, aponta terapeutas ocupacionais que trabalham nessa direção e menciona os pensadores da Filosofia da Diferença, como norteadores de suas ações no campo.

"A leitura dessas autoras e a Esquizoanálise tem me feito companhia em parte das minhas práticas desde a graduação. Acompanhar processos sem um objetivo definido, mas sustentando a relação terapêutica, o desejo $e$ as múltiplas possibilidades de criação é um norte importante do meu trabalho" (Terapeuta 5).

Nota-se que, com exceção de uma entrevistada, todas as demais participantes não adotam um referencial teórico específico da profissão, ou ao menos não o nomeiam, e justificam esse vazio em defesa da flexibilidade de referenciais para demandas complexas ou a imposição de um referencial de campo (Redução de Danos).

A versatilidade interprofissional, mais do que a "filiação à uma ou outra corrente teórica", apresenta maior resolutividade com a população de rua na perspectiva das trabalhadoras entrevistadas. Por outro lado, é necessário alertar para o risco de que a partir de um discurso de flexibilização teórico-prática, terapeutas ocupacionais possam recair em uma simplificação de ações ou em um generalismo que explicita fragilmente as contribuições potentes dessa categoria profissional. A não nomeação das ações de núcleo ou a fragmentação de seus referenciais pode ser entendido como uma prática sem teoria, enfraquecendo a profissão no processo de afirmação de sua singularidade profissional, no processo de composição com outras profissões.

(II) A relação com a equipe

$\mathrm{Na}$ avaliação das entrevistadas, a presença da terapeuta ocupacional nas oficinas terapêuticas e nas atividades cotidianas das equipes do $\mathrm{CnR}$ promovem a aproximação do usuário com a equipe em outra perspectiva que não apenas do cuidado clínico, facilitando a vinculação ao serviço e o acolhimento das necessidades da PSR. A equipe valoriza o papel do terapeuta ocupacional segundo a perspectiva das entrevistadas:

"Vejo também que as ações junto a equipe, na organização dos processos de trabalho e atuação em rede tem feito sentido e contribuindo para o meu processo ali dentro. Bem importante esse reconhecimento e o olhar para essas ações" (Terapeuta 4).

As entrevistadas mencionaram que nos períodos que não ocorre a prática das oficinas, o cuidado em saúde tende a se voltar para um modelo clínico hegemônico.

"A oficina faz muita falta na rua quando não acontece; assim em campos que eu não consigo atuar pela manhã, eles (a equipe do CR) ficam um pouco mais médicoscentrados" (Terapeuta 3).

Os grupos nas oficinas costumam ser abertos, ou seja, a população pode ir e vir, o que torna o aproveitamento deste espaço mais atraente, abrangendo maior número de usuários, por respeitar a dinâmica de vida, que podem estar apenas de passagem ou construindo um vínculo com o serviço, com o território e com o seu cuidado, respeitando o movimento na rua.

$\mathrm{Na}$ perspectiva das entrevistadas a equipe entende a T.O. como uma profissão vinculada primordialmente a oficina de atividades. A Terapeuta 4 conta que levavam essa discussão para equipe, de modo que pudessem reconhecer às ações como uma ação central no cuidado à PSR em busca de um cuidado integral, e não apenas como um atrativo/ entretenimento para os usuários.

\section{A relação com a rua e com os usuários}

A potencialidade do espaço da rua enquanto canal de expressão, criação e cuidado, pode se constituir como um dispositivo essencial para o serviço para a compreensão do cotidiano dos usuários.

Na rua, é possível promover interação entre pessoas 
que se encontram em situação de rua e com aquelas que não estão, como demonstra a Terapeuta 5: "construímos brinquedos juntos e os participantes da oficina experimentaram essas brincadeiras ali na praça. Foi muito potente, pois as pessoas ali ao redor, crianças principalmente, se interessaram e houve uma interação entre todos envolvidos"

As Terapeutas 3 e 4, respectivamente, mencionaram os esforços da equipe do CnR para produção de vínculo que se expressam na rua e em sua dinâmica cotidiana:

\begin{abstract}
"Já fizemos até curativo em cachorro para vincular com o usuário"; "As vezes a gente faz uma busca ativa e se depara com questões do tráfico, com questões da violência nesse território, dai temos que recuar, ir embora para garantir a nossa segurança; ou temos que negociar com traficante para estar naquele espaço, perguntar para ele mesmo, como que a gente poderia estar lá sem atrapalhar, sem acabar com a dinâmica do que estava acontecendo ali, para estar junto desse usuário”.
\end{abstract}

Sobre as potencialidades que o cuidado in loco proporciona aos usuários, a Terapeuta 5 relata que:

\begin{abstract}
"A rua é muito viva! E permite, ao meu ver, uma ampliação das estratégias de cuidado, de invenção desse cuidado, de construção de uma multiplicidade de espaços terapêuticos. Acompanhar os usuários, lado-a-lado, nos seus percursos por um acesso a um cuidado nas unidades de saúde de seu território, criar possibilidades de intervenção e construção de vínculos a partir do território onde vivem, respeitando esse espaço e sua forma de existência, para mim, são as principais potencialidades".
\end{abstract}

Nesse sentido, podemos identificar que para essas terapeutas ocupacionais, a rua é mais do que um espaço de morar ou de trabalhar, mas também um espaço de criação, que expressa uma cotidianeidade própria, atravessada pelo cotidiano de sujeitos individuais e coletivos que habitam singularmente esse espaço. Nesse campo de criação, podem se tecer formas múltiplas de convivência e de encontros para os enfrentamentos das violências que acontecem nos territórios, reinventando-os.

\section{O uso de atividades e o processo terapêutico ocupacional}

Em busca de espaços possíveis para a expressão e criação, o uso de atividades e as oficinas foram citados como os principais dispositivos do trabalho da Terapia Ocupacional no CnR.

Mendonça ${ }^{20}$, aponta que as oficinas permitem ao sujeito um novo modo de estar no mundo, no cuidado consigo mesmo, com o trabalho e com as relações que o cerca ou no acesso a bens culturais.

Galleti $^{21}$, apresenta o trabalho nas oficinas como um dispositivo que permite múltiplas experimentações ao sujeito, de modo que quem participa se visualiza protagonicamente inserido em processos específicos.

Para as entrevistadas, essas práticas funcionam também como um dos meios de acesso $\mathrm{CnR}$, onde o sujeito pode buscar seu cuidado para além das questões clínicas, aproximar-se pela via do desejo de criação e não apenas por sua necessidade em saúde.

Entre fios, tintas e fuxicos, os profissionais são levados a conhecer a história e o contexto de vida de cada pessoa, sua visão de mundo e como se reconhecem em seu cotidiano, em um encontro onde podem coexistir a sutura de uma ferida e a costura de um novo corpo em potencial.

É imprescindível, para a ação terapêutica ocupacional, o aprofundamento e a busca pelo reconhecimento das motivações e desejos que movem os sujeitos, bem como o reconhecimento e elaboração de si como sujeito em relação, dotado de deveres e direitos (muitos negados), na construção do cuidado em saúde, de projetos de vida e na criação de redes de suporte.

Nesta direção, a Terapeuta 5 comenta que o trabalho junto à PSR se dá através da:

"Escuta atenta, o sentar junto, os acompanhamentos, as atividades que realizamos juntos no território (artísticas, artesanais, expressivas, de cuidados com o corpo) são ações de delineiam nosso trabalho (...) potencializar os projetos terapêuticos olhando para os fazeres, ações, atividades significativas dos usuários, dos grupos e territórios que atendemos, com delicadeza, respeitando os projetos e olhando para os desejos das pessoas, criando espaço para eles".

Ferigato $^{22}$ destaca que a atividade promove a visibilidade dos encontros e desencontros que o sujeito lida em seu cotidiano, funcionando como um catalisador de processos de mudanças e de produção da vida, como um motor de experimentação.

"O CnR trabalha com "tecnologias leves, suaves" ... acho que vem muito ao encontro da Terapia Ocupacional. Acredito nisso" (Terapeuta 5).

Para Lancetti ${ }^{13}$, o trabalho dos atores do $\mathrm{CnR}$ produz "novas suavidades" transitando pela dureza, legalista e brutal, de uma parte de nossa sociedade que outra parte não quer ver. 


\section{CONSIDERAÇÕES FINAIS}

A limitação na articulação entre as redes, a dificuldade no acesso aos espaços de saúde, a falta de conhecimento acerca das necessidades da população são fatores que esbarram nas falhas da assistência à saúde e que reverberam no trabalho do $\mathrm{CnR}$, sendo às vezes elementos limitantes e determinantes no cuidado que se é oferecido ao usuário. O cuidado depende dessas redes que distanciam os usuários da sua própria saúde, e distanciam a rua de ser um espaço com maior visibilidade.

Apresentou-se como potência do serviço, o trabalho in loco que permite a ampliação de estratégias de cuidado mais efetivas, diante das inúmeras possibilidades que o território oferece: trocas, produção de subjetividades, produção de cultura, ao sentido do cuidado na rua, a produções de vida.

Está ao alcance do Terapeuta Ocupacional diminuir a distância da PSR com os serviços públicos e com o cuidado de si em um processo afirmativo da vida. Nessa direção, terapeutas ocupacionais produzem vida, produzindo encontros com os usuários através de um conjunto ilimitado de experimentações. Facilita movimentos para que os usuários possam ir em busca de seus desejos e fazeres intensivos, construindo vínculos em seus territórios mediados pela concretude de agir no mundo, alargando possibilidades de existir e resistir. Um trabalho na tecitura de redes com os serviços, entre as pessoas, entre si e com a cidade que habitamos.

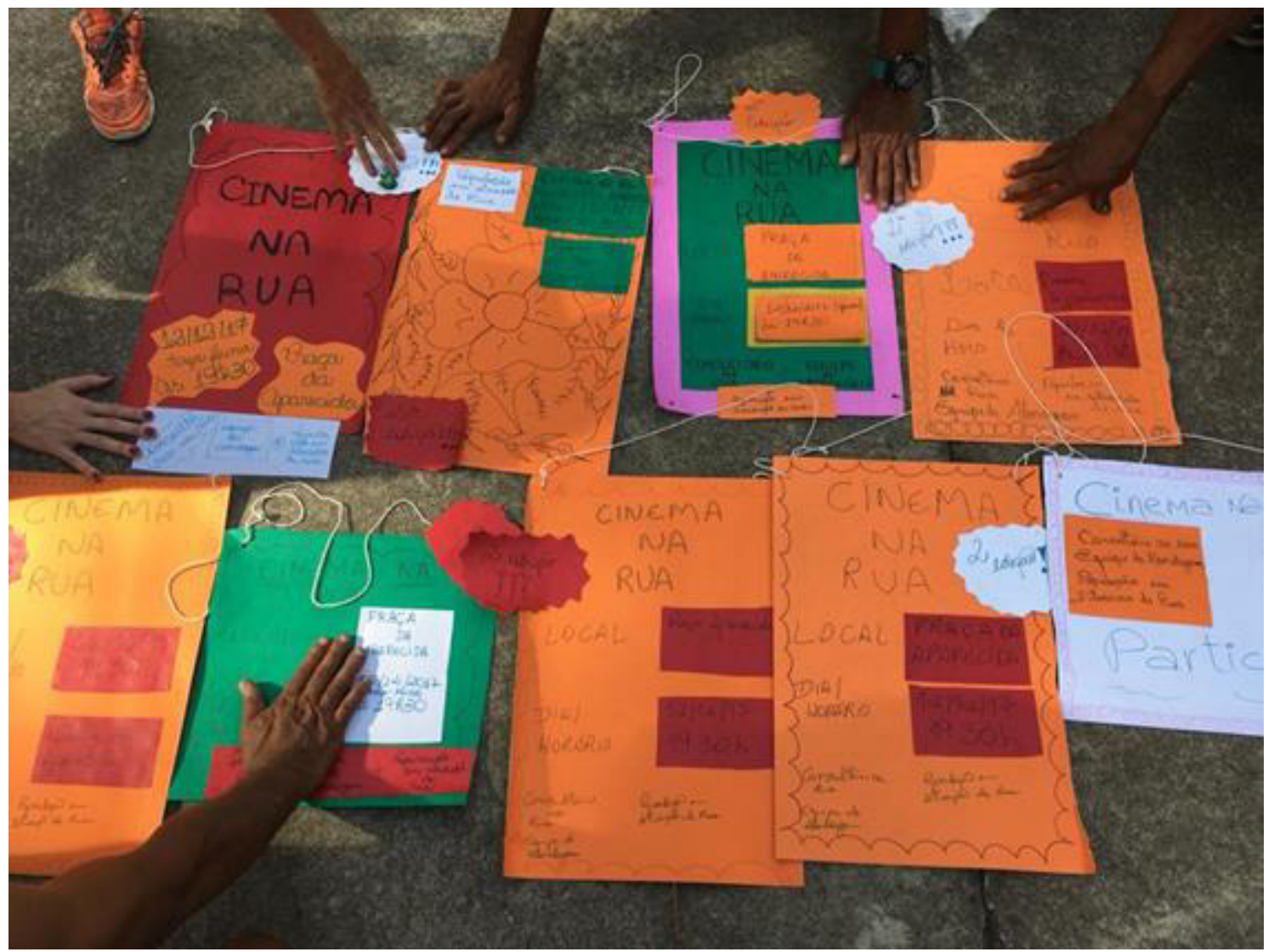

Figura 1. Imagem fornecida por uma das terapeutas ocupacionais entrevistadas sobre as oficinas que acontecem na rua

Este artigo é resultado do trabalho de conclusão de curso intitulado "Corpos de Criação: A Atuação da Terapia Ocupacional no Consultório na Rua" realizado por Camila Prodocimo no curso de graduação em terapia ocupacional da Universidade Federal de São Carlos (UFSCar) sob orientação da Profa. Dra. Sabrina Helena Ferigato e colaborações de Glenda Milek. Camila Prodocimo contribuiu para a produção de dados, análise e redação do texto, Sabrina Ferigato contribuiu com a orientação do trabalho, análise dos dados e redação do texto. Glenda Milek contribuiu na produção de dados e revisão do texto. 


\section{REFERÊNCIAS}

1. Costa APM. População em situação de rua: contextualização e caracterização. Textos Contextos (Porto Alegre). 2006;4(1):115 .

2. Castel R. As armadilhas da exclusão. In: Wanderley, M; Bògus, L; Yazbek, MC. Desigualdade e a questão social. São Paulo: EDUC; 1997.

3. Brasil. Decreto Presidencial n 7.053, de 23 de Dezembro de 2009. Institui a Política Nacional para a População em Situação de Rua e seu Comitê Intersetorial de Acompanhamento e Monitoramento, e dá outras providências. Diário Oficial da União, Brasília, DF, Seção 1, 24 dez. 2009 [citado 17 nov. 2014]. Disponível em: http://www2.camara.leg.br/legin/ fed/decret/2009/decreto-7053-23-dezembro-2009-599156publicacaooriginal-121538-pe.html.

4. Castel R. Da indigência à exclusão, a desfiliação: precariedade do trabalho e vulnerabilidade relacional. In: Lancetti A, organizador. Grupos e coletivos (Saúde, Loucura, n. 4). São Paulo: Hucitec; 1994. p.21-48.

5. Almeida MC, Barros DD, Galvani D, Reis TAM. Terapia ocupacional e pessoas em situação de rua: criando oportunidades e tensionando fronteiras. Cad Ter Ocup. UFSCar (São Carlos). 2011;19(3):351-60. doi: 10.4322/cto.2011.008.

6. Brasil. Ministério da Saúde. Secretaria de Gestão Estratégica e Participativa, Departamento de Apoio à Gestão Participativa. Saúde da população em situação de rua: um direito humano. Brasília: Ministério da Saúde; 2014.

7. Plena MG, Di Giovanni M, Totugui ML, Slva VC, Dalgado PGG, org. Consultório de Rua do SUS. Material de trabalho para a II Oficina Nacional de Consultórios de Rua do SUS. Brasília: Ministério da Saúde/EPJN-FIOCRUZ; 2010.

8. Brasil. Portaria $\mathrm{N}^{\circ} 2.488$, de 21 de outubro de 2011 [citado 20 abr. 2017]. Disponível em: http://bvsms.saude.gov.br/bvs/ saudelegis/gm/2011/prt2488_21_10_2011.html.

9. Brasil. Ministério da Saúde. Departamento da Atenção Básica. Portal do Departamento de Atenção Básica [citado 20 abr. 2018]. Disponível em: http://dab.saude.gov.br/portaldab/ ape_consultorio_rua.php.

10. Londero MFP, Ceccim RB, Bilibio LS. Consultório de/na rua: desafio para um cuidado em verso na saúde. Interface (Botucatu). 2014;18(49):251-60. dx.doi.org/10.1590/180757622013.0738 .

11. Brasil. Ministério da Saúde. Departamento da Atenção Básica. Portal: Observatório Crack, é possível vencer [citado 20 abr. 2017]. Disponível em: http://www.brasil.gov.br/ observatoriocrack.

12. Jorge JS, Corradi-Webster CM. Consultório de rua: contribuições e desafios de uma prática em construção. Saúde Transform Soc (Florianópolis). 2012;3(1):39-48.

13. Lancetti, A. Contrafissura e plasticidade psíquica. São Paulo: Hucitec; 2015.

14. Lopes RE, Palma AM, Reis TAM. A experimentação teóricoprática do aluno de Terapia Ocupacional no campo social: uma vivência com a população em situação de rua. Rev Ter Ocup Univ São Paulo. 2005;16(2):54-61. https://doi.org/10.11606/ issn.2238-6149.v16i2p54-61

15. Barros DD. Terapia ocupacional social: o caminho se faz ao caminhar. Rev Ter Ocup Univ São Paulo. 2004;15(3):90-7. doi:/10.11606/issn.2238-6149.v15i3p90-97

16. Vinuto J. A amostragem em bola de neve na pesquisa qualitativa: um debate em aberto. Temáticas. 2016(44):203-20.

17. Minayo MCS. O desafio da pesquisa social. In: Pesquisa social: teoria, método e criatividade. 14a ed. Petrópolis: Vozes; 1999.

18. Campos GWS. Saúde pública e saúde coletiva: campo e núcleo de saberes e práticas. Ciênc Saúde Coletiva. 2000;5(2):219-30. DOI:/10.1590/S1413-81232000000200002.

19. Brasil. Manual sobre o cuidado à saúde junto à população em situação de rua, 2012 [5 mar. 2018]. Disponível em: http://189.28.128.100/dab/docs/publicacoes/geral/manual_ cuidado populalcao_rua.pdf.

20. Mendonça TCP. As oficinas na saúde mental: relato de uma experiência na internação. Psicol Cienc Prof (Brasília). 2005;25(4):626-35. doi:/10.1590/S1414-98932005000400011.

21. Galleti MC. Oficina em saúde mental: instrumento terapêutico ou intercessor clínico? Goiânia: Ed. da UCG; 2004.

22. Ferigato SH. O agir criativo em Terapia Ocupacional: uma reflexão filosófica a partir dos paradoxos da contemporaneidade. Cad Ter Ocup UFSCar. 2010;15(2):131-7. 